\title{
A Planted Forest Mapping Method Based on Long-Term Change Trend Features Derived from Dense Landsat Time Series in an Ecological Restoration Region
}

\author{
Yuanyuan Meng ${ }^{1}$, Caiyong Wei ${ }^{2,3}$, Yanpei Guo ${ }^{1}$ (D) and Zhiyao Tang ${ }^{1, *(\mathbb{D}}$ \\ 1 Institute of Ecology, College of Urban and Environmental Sciences and Key Laboratory for Earth Surface \\ Processes, Peking University, Beijing 100871, China; mengyy@pku.edu.cn (Y.M.); \\ guoyanpei@pku.edu.cn (Y.G.) \\ 2 School of Information Engineering, China University of Geosciences, Beijing 100083, China; \\ weicaiyong@cugb.edu.cn \\ 3 Ningxia Institute of Remote Sensing Survey, Yinchuan 750021, China \\ * Correspondence: zytang@urban.pku.edu.cn
}

check for updates

Citation: Meng, Y.; Wei, C.; Guo, Y.; Tang, Z. A Planted Forest Mapping Method Based on Long-Term Change Trend Features Derived from Dense Landsat Time Series in an Ecological Restoration Region. Remote Sens. 2022, 14, 961. https://doi.org/ $10.3390 /$ rs 14040961

Academic Editors: Bingfang Wu, Yuan Zeng and Dan Zhao

Received: 29 December 2021 Accepted: 13 February 2022 Published: 16 February 2022

Publisher's Note: MDPI stays neutral with regard to jurisdictional claims in published maps and institutional affiliations.

Copyright: (c) 2022 by the authors. Licensee MDPI, Basel, Switzerland. This article is an open access article distributed under the terms and conditions of the Creative Commons Attribution (CC BY) license (https:// creativecommons.org/licenses/by/ $4.0 /)$.

\begin{abstract}
Planted forests provide a variety of meaningful ecological functions and services, which is a major approach for ecological restoration, especially in arid areas. However, mapping planted forests with remote-sensed data remains challenging due to the similarities in canopy spectral and structure characteristics and associated phenology features between planted forests and other vegetation types. In this study, taking advantage of the Google Earth Engine (GEE) platform and taking the Ningxia Hui Autonomous Region in northwestern China as an example, we developed an approach to map planted forests in an arid region by applying long-term features of the NDVI derived from dense Landsat time series. Our land cover map achieved a satisfactory accuracy and relatively low uncertainty, with an overall accuracy of $93.65 \%$ and a kappa value of 0.92 . Specifically, the producer (PA) and user accuracies (UA) were $92.48 \%$ and $91.79 \%$ for the planted forest class, and $93.88 \%$ and $95.83 \%$ for the natural forest class, respectively. The total planted forest area was estimated as $3608.72 \mathrm{~km}^{2}$ in 2020 , accounting for $20.60 \%$ of the study area. The proposed mapping approach can facilitate assessment of the restoration effects of ecological engineering and research on ecosystem services and stability of planted forests.
\end{abstract}

Keywords: planted forests; long-term change trend features; Landsat time series; Google Earth Engine; random forest; NDVI

\section{Introduction}

Afforestation and reforestation are widely applied to restore disturbed ecosystems, to combat desertification and soil erosion, and to mitigate carbon emissions [1,2]. To restore the disturbed ecosystems, China has implemented a series of ecological programs, such as the Three-North Shelterbelt Program (since 1978), the Grain for Green Program (since 1999), and the Natural Forest Conservation Program (since 2000) [3,4]. Owing to the ecological programs, greening has been observed in northern China [5]. However, the contribution of afforestation is ambiguous, as planted forests are distributed dispersedly and cannot be separated from natural forests at large scales [6]. Natural and planted forests provide different aspects of ecosystem services [7]. A precise map of both forest types can explicitly locate the planted forest expansion and natural forest loss [8]. In contrast, forest assessments without distinguishing planted from natural forests may underestimate forest change $[9,10]$. Therefore, fine-resolution mapping of planted forests is essential to not only assess ecosystem service and stability, but also evaluate the restoration effects of ecological programs [11].

Remote sensing is widely employed in land cover mapping, especially for forest monitoring [12,13]. Many studies have explored the feasibility of Landsat images in 
planted forest mapping [10,14], mostly based on the following three types of characteristics: multispectral features $[15,16]$, canopy texture $[17,18]$, and phenological insights [19-21]. From spectral, structural, and temporal perspectives, planted forests are characterized by faster growth, single-species monocultures, and shorter harvest rotation periods, compared to the counterparts of natural forests, respectively $[22,23]$. These characteristics function well in separating planted economic trees from natural forests. However, two challenges remain for planted forests identification in ecological restoration regions. First, the spectral and structural signatures of planted forests are similar to those of other vegetation types at different growing stages. For example, young or sparse forests are similar to cropland and grasslands regarding to spectral signatures, and mature plantations are similar to natural forests $[6,22,24]$. Second, phenology-based features cannot discriminate plantations from natural forests when plantations contain similar species to those in natural forests. The implementation modes of ecological engineering and characteristics, such as the species, soil backgrounds, and disturbances result in high diversity and variability of planted forests, which cannot be characterized based on universally identifiable phenological features $[25,26]$.

The long-term growth metrics and change event characteristics of time series are promising for planted forest identification, which has been highlighted in extracting pine and rubber plantation $[10,23]$. Tree plantation is a process ranging from non-forested to forested areas, followed by continuously growing process in subsequent years, during which, their vegetation activity, as reflected by the vegetation index (VI), steadily increases [27]. In this sense, the subsequent VI of newly planted forests are slightly higher than those in previous years. In contrast, the VI of natural vegetation types fluctuate throughout the different seasons over time [22,24]. Including the long-term trend characteristics into planted forest identification is helpful to tackle above challenges.

In this paper, we took a semiarid ecological restoration region in the Ningxia Hui Autonomous Region in northwestern China as an example, and employed long-term change trend features derived from dense Landsat time series and random forest classification on the Google Earth Engine (GEE) platform to provide new insights into planted forest mapping.

\section{Materials and Methods}

There are four major steps in our mapping approach: (a) data preprocessing, (b) multifaceted feature extraction, (c) reference sample collection, and (d) classification, validation and accuracy assessment (Figure 1).

\subsection{Materials}

\subsubsection{Study Area}

The study was conducted in a semiarid region in South Ningxia, with a longitude of $105^{\circ} 12^{\prime}-106^{\circ} 57^{\prime} \mathrm{E}$ and a latitude of $35^{\circ} 15^{\prime}-36^{\circ} 57^{\prime} \mathrm{N}$, and a total area of $17,452 \mathrm{~km}^{2}$. The area is at the southern mountainous and loess hilly area in the central-western part of the Loess Plateau (Figure 2). The area is of a typical temperate continental monsoon climate, with annual mean temperature ranging from $-9{ }^{\circ} \mathrm{C}$ to $24^{\circ} \mathrm{C}$, annual precipitation ranging from $180 \mathrm{~mm}$ in the north to $800 \mathrm{~mm}$ in the south $(80 \%$ of which was precipitated in summer and autumn) and annual surface evaporation of $1250 \mathrm{~mm}$. The Chinese government implemented a series of policies and programs to manage the serious ecological problems encountered within this region [13]. However, high aridity, extensive human activities, and long-term soil erosion have resulted in ecological vulnerability and sensitivity, which make the survival and growth of planted forests difficult [28]. 


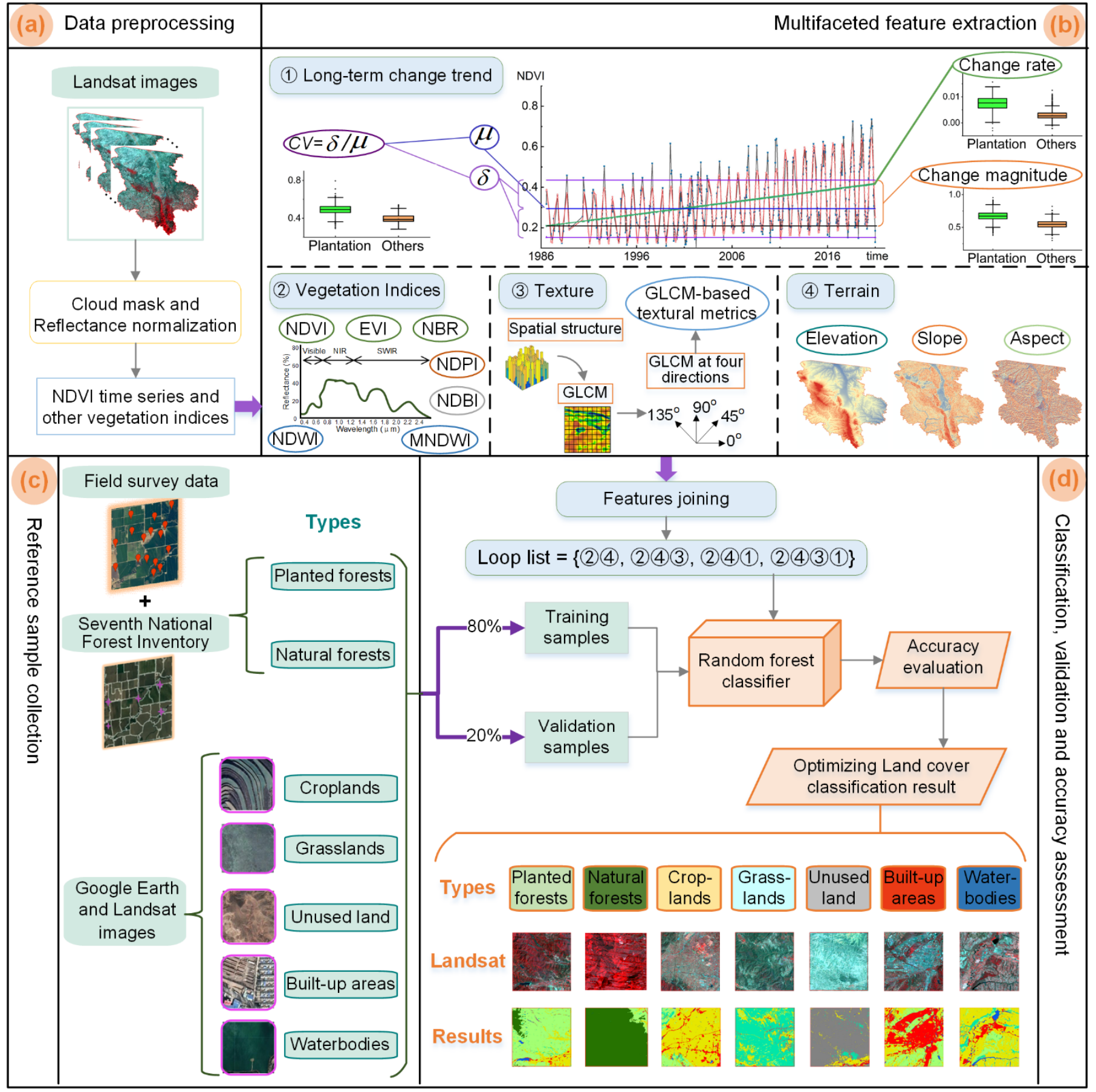

Figure 1. Framework for mapping the planted forests in this study: (a) data preprocessing, (b) multifaceted feature extraction, (c) reference sample collection, and (d) classification, validation and accuracy assessment. GLCM denotes the gray-level cooccurrence matrix, $\mu$ and $\sigma$ denote the mean and standard deviation of the time series, and $c v$ denotes the coefficient of variation of the time series. The various vegetation indices (VIs) are listed in Table A1 (Appendix A).

\subsubsection{Landsat Time Series Processing}

All available Landsat 5, 7, and 8 surface reflectance data from 1986 to 2020 were compiled and processed on the GEE platform. Systematic atmospheric and terrain corrections were conducted to produce a Level-1 precision product [29]. In total, 460 Landsat scenes with less than $30 \%$ cloud cover were assembled, with an average of 13 images per year (Figure 3a). Observations of individual pixels were processed with the CFmask algorithm, 
which can identify clouds and cloud shadows [30]. To get the consistent data among Landsat sensors, we harmonized Landsat TM and ETM+ data into OLI data according to Roy et al. (2016) on the GEE platform [31] (https:/ / developers.google.com/earth-engine/ tutorials/community/landsat-etm-to-oli-harmonization, accessed on 10 August 2021). Several vegetation indices (VIs) were calculated and applied as input features for classification (see the full list in Table A1, Appendix A). Among these indices, the normalized difference vegetation index (NDVI) was employed to calculate the long-term change trend and textural metrics [32].
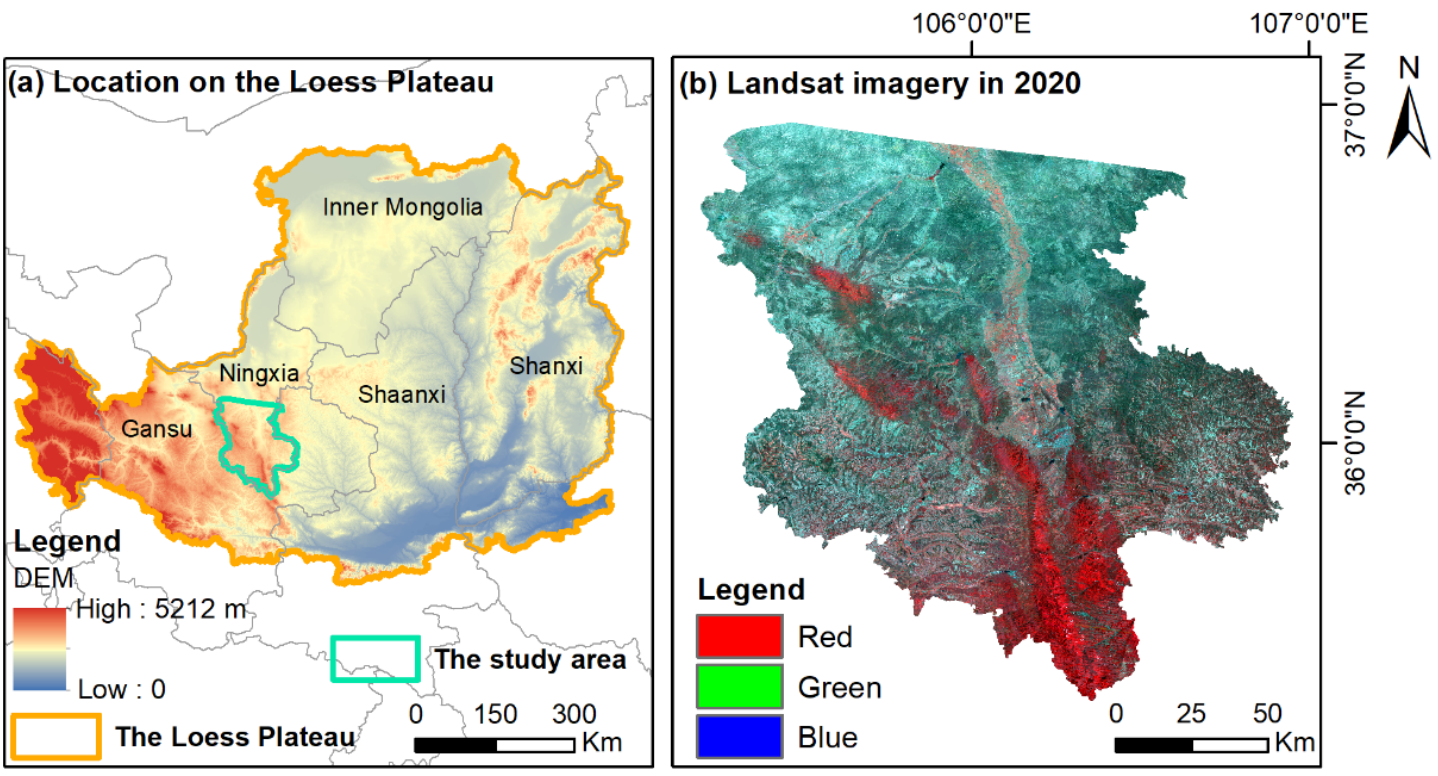

Figure 2. Location of the study area on the Loess Plateau based on a digital elevation model (DEM) (a), and (b) annual composite Landsat imagery (red-green-blue bands) based on the median reflectance in 2020 .

(a) Observation number of images

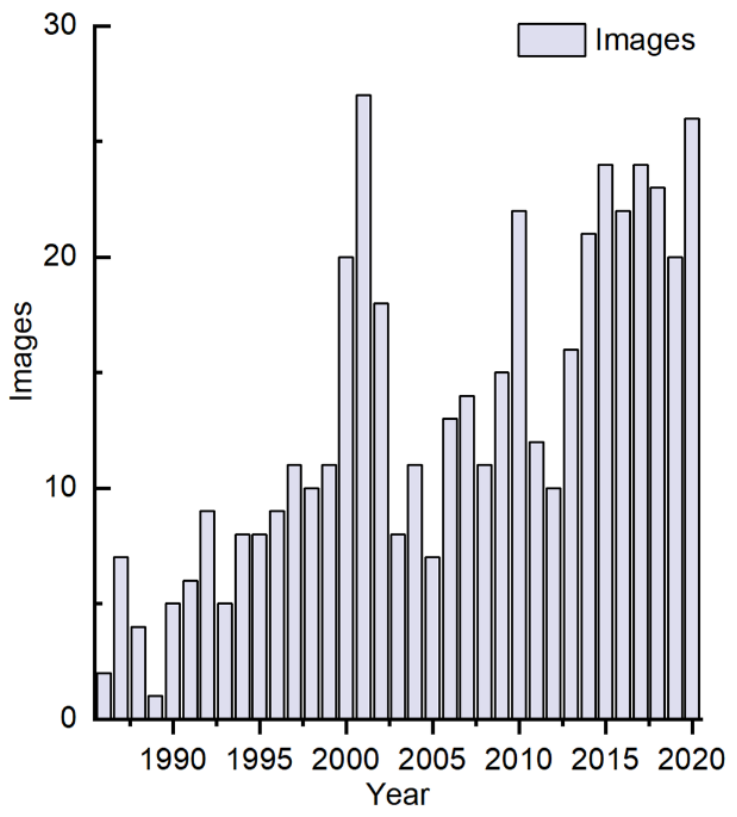

(b) Reference sample data

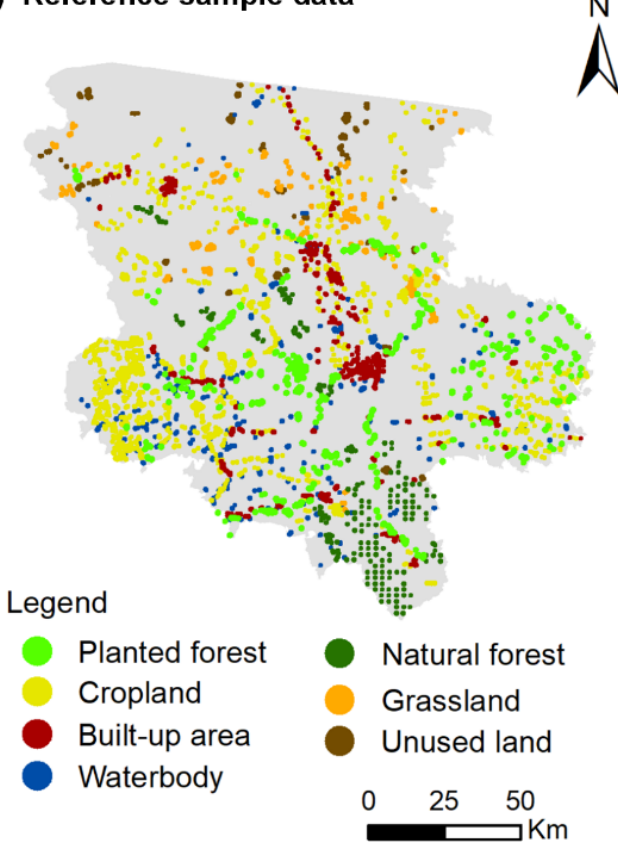

Figure 3. Observation number of images per year in the study area (a), and (b) spatial distribution of the reference sample data in the study area. 


\subsection{Multifaceted Feature Extraction}

The change rate, change magnitude, mean $(\mu)$, standard deviation $(\sigma)$, and coefficient of variation (cv) of the NDVI over a long time series (from 1986 to 2020) were employed to illustrate the long-term change trend features (Figure 1b). Although planted forests exhibit similar features to those of natural forests and other vegetation types, the long-term change trend characteristics provide the potential to distinguish planted forests from other vegetations. Changes in land cover, such as the conversion of barren land to grassland and farmland reclamation, may exhibit different dynamics in NDVI from that of tree growth of the planted forests. The NDVIs change sharply in the second year after the conversion of barren land to grassland or farmland reclamation and then remain stable, whilst the NDVIs of the newly planted forests change continuously [22,24]. Due to the specific growth process, planted forests exhibited notable variation in the change rate, mean $(\mu)$, standard deviation $(\sigma)$ of long-term NDVI time series (Figure 4a,c,d). Additionally, mainly due to the recent national forestation campaigns implemented, planted forests are characterized by relatively young age and sparse distribution [33]. In contrast, natural forests attain higher mean NDVI values than other vegetation types (i.e., newly planted forests and croplands) over long periods [20]. Consequently, standard deviation $(\sigma)$ and coefficient of variation (cv) of the NDVI could be determined to discriminate planted forests from other vegetation types, as their values should be higher for planted forests. Planted forests and other three vegetation types could be easily distinguished according to the long-term trend features of the reference samples (Figure 4). In addition to long-term change trend features, we calculated other widely considered features, including textural and terrain metrics, in the following sections.

(a) Change rate

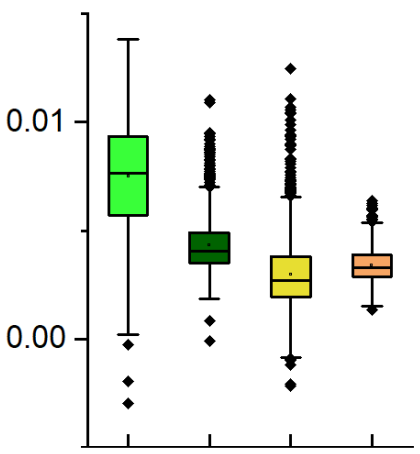

(c) Mean

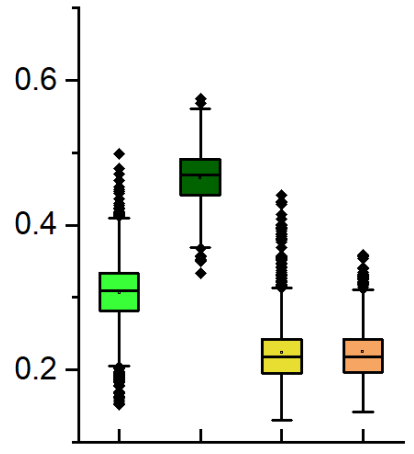

(b) Change magnitude

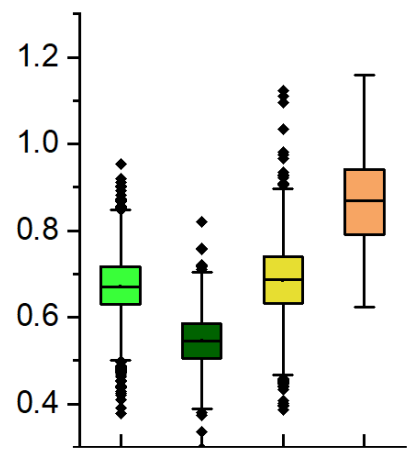

(d) Standard deviation

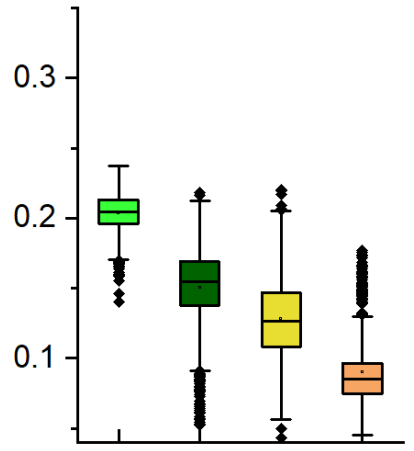

Legend

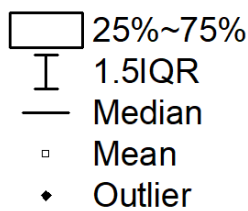

- Outlier

Planted forest

Natural forest

Cropland

Grassland

(e) Coefficient of variation

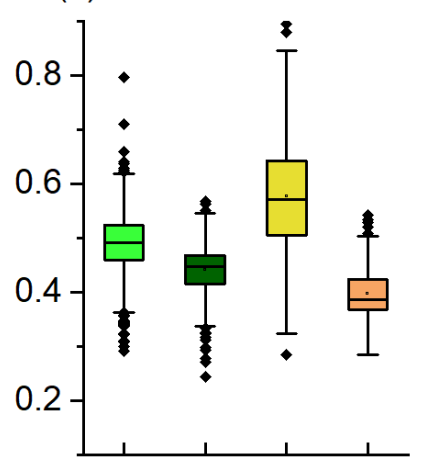

Figure 4. Box plot of vegetation reference samples of the long-term time series of the NDVI: (a) change rate, $(\mathbf{b})$ change magnitude, $(\mathbf{c})$ mean $(\mu)$, (d) standard deviation $(\sigma)$, and (e) coefficient of variation $(\mu / \sigma)$ of different vegetation types (planted forest, natural forest, cropland and grassland).

\subsubsection{Long-Term Change Trend Features}

Based on all available Landsat data on the GEE platform, we analyzed long-term trend features with the harmonic analysis of time series (HANTS) algorithm. This approach 
is useful to harmonize Landsat time series with the phenological cycles. The HANTS algorithm not only de-clouds and reconstructs remote sensing time series but also is advantageous for placing fewer requirements on the input image data, of which the time interval can be unequal [34]. We assembled about 10-20 (or more) observations in most years, which were sufficient to fit the harmonic model (Figure 3a). The HANTS algorithm considers both the seasonal change and characteristics of data to truly reflect the periodic changes in vegetation during time series reconstruction. We first decomposed the complex time series signal into a function of individual sine or cosine waves based on the Fourier series [35]:

$$
\tilde{\mathrm{f}}_{\mathrm{t}}=\mathrm{c}_{0}+\sum_{\mathrm{i}=1}^{\mathrm{n}}\left(\mathrm{a}_{\mathrm{i}} \cos \frac{\mathrm{i} 2 \pi \mathrm{t}}{\mathrm{m}}+\mathrm{b}_{\mathrm{i}} \sin \frac{\mathrm{i} 2 \pi \mathrm{t}}{\mathrm{m}}\right)
$$

where $t$ is the timestamp value composited by harmonic regression, $m$ is the length of the seasonal change, and $\mathrm{n}$ is the order of the polynomial and approximately equal to the number of harmonics. Second, ordinary least squares (OLS) regression was employed to estimate the observations, and a composite Fourier series was adopted to determine the best-fit model against the original time series values. Then, the estimated coefficients $\left(c_{0}, a_{i}\right.$, and $b_{i}$ ) were stored to obtain a fitted harmonic series, seasonal change, and residual errors:

$$
F_{t}=\beta_{0}+\beta_{1} t+\beta_{2} \cos (2 \pi \omega t)+\beta_{3} \sin (2 \pi \omega t)+e_{t}
$$

where $F_{t}$ is the harmonic fit, $\beta_{0}$ and $\beta_{1}$ are the linear regression coefficients, $\beta_{2}$ and $\beta_{3}$ are coefficients based on the Fourier series, $\omega$ is the frequency, and $t$ is the timestep. Finally, the harmonic series data were substituted into the linear regression model to obtain the change rate and magnitude. The mean $(\mu)$ and standard deviation $(\sigma)$ of the original long-term time series of the NDVI were computed pixel by pixel, and the coefficient of variation (cv) could then be obtained with the following equation:

$$
\mathrm{cv}=\frac{\sigma}{\mu}
$$

\subsubsection{Textural Metrics}

We obtained the median cloud-free NDVI imagery for the year 2020, and calculated the joint probability distribution of pairs of gray levels $\left(\mathrm{C}_{\mathrm{ij}}\right)$ as a function of the gray-level cooccurrence matrix (GLCM) [36,37], which is defined by the NDVI composite collection for 2020 using median values:

$$
C_{i j}=\left\{\frac{P_{i j}}{\sum_{i, j=1}^{G} P_{i j}} \mid(\delta, \theta)\right\}
$$

where $P_{\mathrm{ij}}$ is the count of NDVI occurrences, $\delta$ is the distance between two pixels (here, $\delta=1$ ), $G$ is the quantized number of gray levels (here, $G=256$ ), and $\theta$ is the orientation $\left(\theta=0^{\circ}, 45^{\circ}, 90^{\circ}\right.$, and $\left.135^{\circ}\right)$.

We calculated eight widely used texture features based on the GLCM method (Table A2). We tested the eight metrics under different window sizes, and the top six high-importance features (considering the sum of the averages under the five window sizes and the correlation at $64 \times 64$ pixels) of the textural metrics were employed in our method (Figure A1).

\subsubsection{Terrain Metrics}

The Shuttle Radar Topography Mission V3 product (SRTM Plus) provided by NASA JPL yielded digital elevation models (DEMs) at a resolution of 1 arc-second (approximately $30 \mathrm{~m}$ ) [38]. We calculated images containing bands of the elevation, slope, and aspect according to the terrain DEM as input features in this study. 


\subsection{Reference Sample Collection}

\subsubsection{Field Sampling Data}

The required but rarely recorded forest origin information (natural or plantation) in field measurements is central to the difficulty in planted forest identification [24]. We determined the forest types that could not be identified from the obtained Landsat and high-resolution images based on field-sampled data.

One source was the Seventh National Forest Inventory (NFI 7th) surveyed from 20042008 , in which attribute information such as land types and forest origins were adopted. According to the Technical Regulation for the national forest inventory, the position errors of coordinates of the NFI 7th plot data were less than $15 \mathrm{~m}$ at the GPS location. We first selected natural forests by evaluating the forest origin. After eliminating non-forest pixels in Landsat and Google Earth images for 2020, 135 natural forest pixels were labeled.

In addition, we conducted a field survey of the forest types on the Loess Plateau from July to August 2021. LocaSpace Viewer (http:/ / uatwww.locaspace.cn/ (accessed on 10 August 2021)) was applied to collect location information on the sampled planted forests (695 pixels) and natural forests (120 pixels).

\subsubsection{Reference Data Based on Images}

We visually assessed the other landcover types via Landsat and high-resolution Google Earth images for 2020, which is a practical sampling method that can distinguish samples with a satisfactory accuracy [13]. There were 4500 pixels labeled as reference data for training and validation purposes in this study (Figure $3 b$ and Table 1).

Table 1. Numbers of reference pixels and their sources for each land cover type.

\begin{tabular}{ccccc}
\hline $\begin{array}{c}\text { Land Cover } \\
\text { Types }\end{array}$ & $\begin{array}{c}\text { Field Survey } \\
\text { Data }\end{array}$ & $\begin{array}{c}\text { 7th National } \\
\text { Forest } \\
\text { Inventory }\end{array}$ & Image Data & Total Number \\
\hline Planted forest & 695 & 0 & 0 & 695 \\
Natural forest & 120 & 135 & 0 & 255 \\
Cropland & 0 & 0 & 1406 & 1406 \\
Grassland & 0 & 0 & 722 & 722 \\
Unused land & 0 & 0 & 438 & 438 \\
Built-up area & 0 & 0 & 520 & 520 \\
Waterbody & 0 & 0 & 464 & 464 \\
Total number & 815 & 135 & 3550 & 4500 \\
\hline
\end{tabular}

\subsection{Classification, Validation and Accuracy Assessment}

The long-term change trend, VI, texture, and terrain features extracted above were sequentially fed into random forest (RF) models to classify land cover into seven types, i.e., planted forest, natural forest, cropland, grassland, unused land, built-up area, and waterbody (Table A3). To assess the effectiveness of long-term change trend characteristics and optimize the classification results, we selected VIs and terrain features as input features first, then sequentially included texture and the long-term change trend and finally jointly input all these features (Figure 1d).

We divided the 4500 reference pixels into training (80\%) and validation $(20 \%)$ sets through random splitting. After employing a confusion matrix to compute the user accuracy (UA), producer accuracy (PA), and overall accuracy (OA) to determine the input feature performance [39], we obtained land cover results with the optimal input features.

The uncertainty analysis is coupled with an assessment of the classification accuracy at the overall, class-, and pixel-levels. For probabilistic classifiers, the classification uncertainty is characterized by the posterior probabilities that a pixel belongs to different land cover classes [40]. The RF classifier provided information on the pixel-level uncertainty in this study, which was calculated by 1-Pmax, with Pmax the maximum probability of being classified as each land cover class [41]. In addition, we applied the ee.pixelArea() function 
to compute the land cover area on the GEE platform, which considered the difference in pixel size change with the latitude and longitude (due to projection).

\section{Results}

After considering long-term change trend metrics, the PA and UA of the planted forest class improved from both approximately $76 \%$ to $86 \%$ and $92 \%$, respectively. Similarly, the PA and UA of the natural forest class improved from approximately $69 \%$ and $88 \%$ to $100 \%$ and $92 \%$, respectively. When combining the long-term change trend and texture metrics as input features, the accuracy of the planted forest class improved from approximately $76 \%$ to over $90 \%$. Contrast analysis confirmed that trend features were crucial for planted forest identification, which improved the separability and guaranteed the classification accuracy across the different vegetation types (Table 2 and Figures 5a and A2).

Table 2. User accuracy (UA), producer accuracy (PA), and overall accuracy (OA) of the seven land cover types using the vegetation index (VI), using VI and GLCM-based textural metrics, using VI and long-term change trend metrics, and using VI, textural metrics, and long-term change trend metrics. The PA and UA for the planted and natural forest class, OA, and kappa coefficient were illustrated in bold.

\begin{tabular}{|c|c|c|c|c|c|c|c|c|c|}
\hline $\begin{array}{c}\text { Land Cover } \\
\text { Types }\end{array}$ & $\begin{array}{c}\text { Planted } \\
\text { Forest }\end{array}$ & $\begin{array}{c}\text { Natural } \\
\text { Forest }\end{array}$ & $\begin{array}{l}\text { Crop- } \\
\text { Land }\end{array}$ & $\begin{array}{l}\text { Grass- } \\
\text { Land }\end{array}$ & $\begin{array}{c}\text { Unused } \\
\text { Land }\end{array}$ & $\begin{array}{c}\text { Built-Up } \\
\text { Area }\end{array}$ & $\begin{array}{l}\text { Water- } \\
\text { Body }\end{array}$ & Total & PA \\
\hline \multicolumn{10}{|c|}{ Using the vegetation index (VI) } \\
\hline Planted forest & 100 & 4 & 7 & 17 & 1 & 0 & 1 & 130 & $76.92 \%$ \\
\hline Natural forest & 16 & 37 & 0 & 0 & 0 & 0 & 0 & 53 & $69.81 \%$ \\
\hline Cropland & 4 & 0 & 242 & 10 & 2 & 6 & 0 & 264 & $91.67 \%$ \\
\hline Grassland & 10 & 1 & 2 & 112 & 6 & 0 & 0 & 131 & $85.50 \%$ \\
\hline Unused land & 0 & 0 & 8 & 3 & 68 & 1 & 0 & 80 & $85.00 \%$ \\
\hline Built-up area & 0 & 0 & 21 & 0 & 1 & 94 & 0 & 116 & $81.03 \%$ \\
\hline Waterbody & 1 & 0 & 3 & 0 & 2 & 1 & 93 & 100 & $93.00 \%$ \\
\hline Total & 131 & 42 & 283 & 142 & 80 & 102 & 94 & \multirow{2}{*}{\multicolumn{2}{|c|}{$\begin{array}{l}\text { OA } 85.35 \% \\
\text { Kappa } 0.82\end{array}$}} \\
\hline UA & $76.34 \%$ & $88.10 \%$ & $85.51 \%$ & $78.87 \%$ & $85.00 \%$ & $92.16 \%$ & $98.94 \%$ & & \\
\hline \multicolumn{10}{|c|}{ Using VI and GLCM-based textural metrics } \\
\hline Planted forest & 105 & 3 & 8 & 9 & 3 & 0 & 1 & 129 & $81.40 \%$ \\
\hline Natural forest & 10 & 37 & 1 & 3 & 0 & 0 & 0 & 51 & $72.55 \%$ \\
\hline Cropland & 8 & 2 & 252 & 5 & 6 & 6 & 0 & 279 & $90.32 \%$ \\
\hline Grassland & 8 & 2 & 3 & 131 & 3 & 0 & 0 & 147 & $89.12 \%$ \\
\hline Unused land & 0 & 0 & 5 & 8 & 72 & 1 & 0 & 86 & $83.72 \%$ \\
\hline Built-up area & 0 & 0 & 10 & 1 & 1 & 106 & 5 & 123 & $86.18 \%$ \\
\hline Waterbody & 3 & 0 & 5 & 0 & 0 & 0 & 79 & 87 & $90.80 \%$ \\
\hline Total & 134 & 44 & 284 & 157 & 85 & 113 & 85 & \multirow{2}{*}{\multicolumn{2}{|c|}{$\begin{array}{l}\text { OA } 85.73 \% \\
\text { Kappa } 0.83\end{array}$}} \\
\hline UA & $78.36 \%$ & $84.09 \%$ & $88.73 \%$ & $83.44 \%$ & $84.71 \%$ & $93.81 \%$ & $92.94 \%$ & & \\
\hline \multicolumn{10}{|c|}{ Using VI and long-term change trend metrics } \\
\hline Planted forest & 116 & 4 & 7 & 7 & 0 & 0 & 0 & 134 & $86.57 \%$ \\
\hline Natural forest & 0 & 42 & 0 & 0 & 0 & 0 & 0 & 42 & $100.00 \%$ \\
\hline Cropland & 8 & 0 & 268 & 0 & 2 & 3 & 0 & 281 & $95.37 \%$ \\
\hline Grassland & 1 & 0 & 2 & 132 & 1 & 0 & 0 & 136 & $97.06 \%$ \\
\hline Unused land & 0 & 0 & 2 & 7 & 79 & 4 & 0 & 92 & $85.87 \%$ \\
\hline Built-up area & 0 & 0 & 3 & 0 & 0 & 97 & 4 & 104 & $93.27 \%$ \\
\hline Waterbody & 0 & 0 & 3 & 0 & 0 & 3 & 94 & 100 & $94.00 \%$ \\
\hline Total & 125 & 46 & 285 & 146 & 82 & 107 & 98 & \multirow{2}{*}{\multicolumn{2}{|c|}{$\begin{array}{l}\text { OA } 93.14 \% \\
\text { Kappa } 0.91\end{array}$}} \\
\hline UA & $92.80 \%$ & $91.30 \%$ & $94.04 \%$ & $90.41 \%$ & $96.34 \%$ & $90.65 \%$ & $95.92 \%$ & & \\
\hline \multicolumn{10}{|c|}{ Using VI, textural metrics, and long-term change trend metrics } \\
\hline Planted forest & 123 & 1 & 4 & 4 & 0 & 1 & 0 & 133 & $92.48 \%$ \\
\hline Natural forest & 3 & 46 & 0 & 0 & 0 & 0 & 0 & 49 & $93.88 \%$ \\
\hline Cropland & 5 & 0 & 259 & 0 & 2 & 3 & 0 & 269 & $96.28 \%$ \\
\hline Grassland & 2 & 1 & 2 & 143 & 5 & 0 & 0 & 153 & $93.46 \%$ \\
\hline Unused land & 1 & 0 & 3 & 5 & 75 & 3 & 0 & 87 & $86.21 \%$ \\
\hline Built-up area & 0 & 0 & 4 & 0 & 1 & 109 & 2 & 116 & $93.97 \%$ \\
\hline Waterbody & 0 & 0 & 2 & 0 & 1 & 2 & 85 & 90 & $94.44 \%$ \\
\hline Total & 134 & 48 & 274 & 152 & 84 & 118 & 87 & \multirow{2}{*}{\multicolumn{2}{|c|}{$\begin{array}{l}\text { OA } 93.65 \% \\
\text { Kappa } 0.92\end{array}$}} \\
\hline UA & $91.79 \%$ & $95.83 \%$ & $94.53 \%$ & $94.08 \%$ & $89.29 \%$ & $92.37 \%$ & $97.70 \%$ & & \\
\hline
\end{tabular}


(a) Land cover map

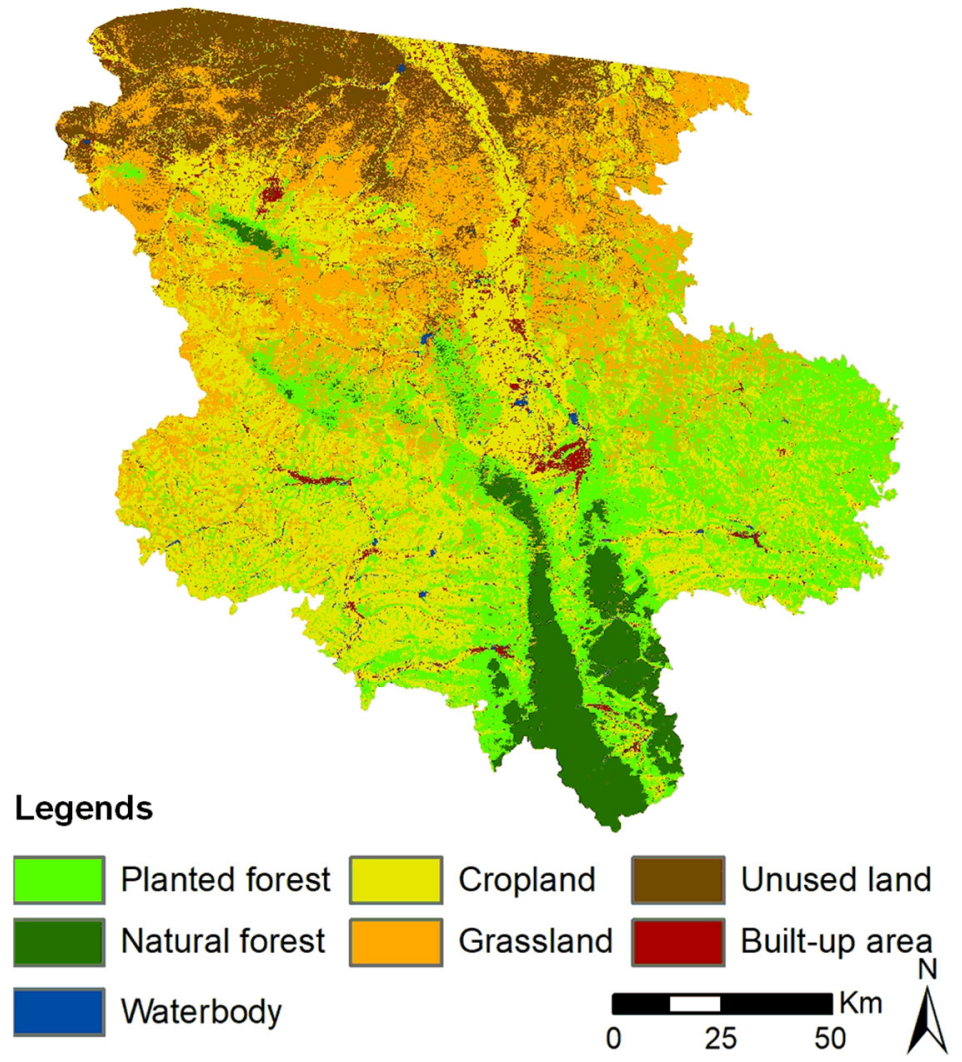

(b) Area and proportion of each land cover type

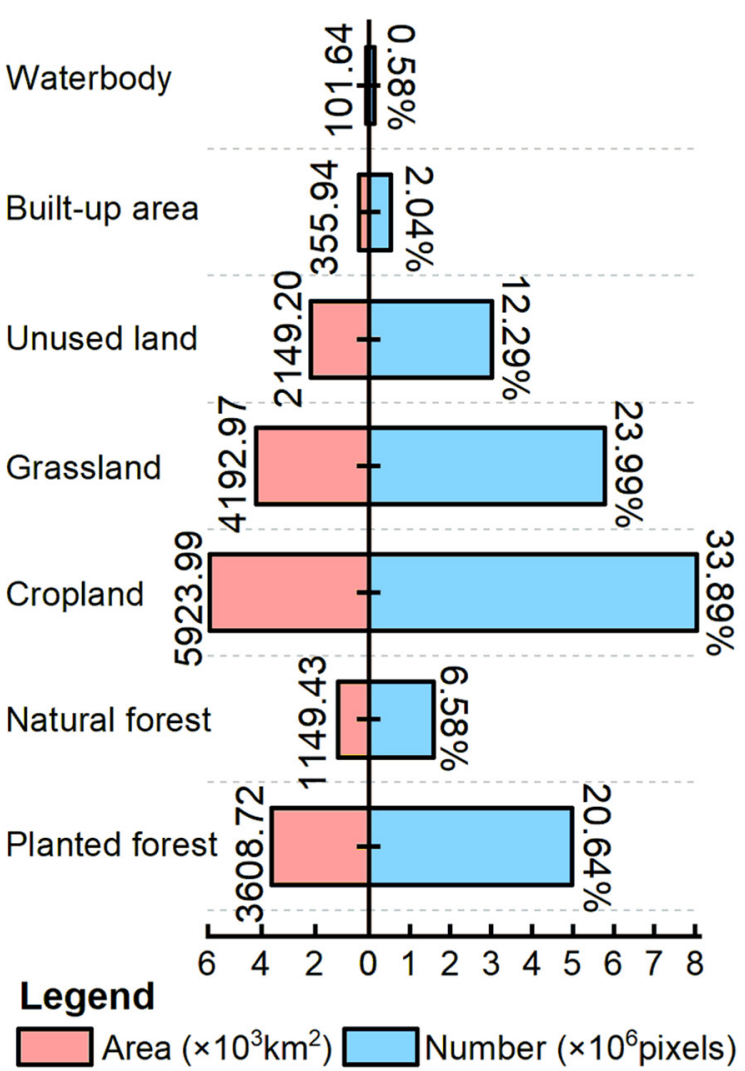

Figure 5. (a) Land cover map and, (b) area and number of pixels of each land cover type in the study area.

After using VI, textural metrics, and long-term change trend metrics, the OA reached 93.65\%. The PA and UA were $92.48 \%$ and $91.79 \%$ for the planted forest, $93.88 \%$ and $95.83 \%$ for the natural forest, and $86.21 \%$ and $89.29 \%$ for the unused land, respectively. The other classes attained PA and UA values over $90 \%$. In addition, the kappa coefficient reached 0.92, indicating that the classification method performed well (Table 2).

Natural forests were mainly concentrated in the Liupan Mountain District. Planted forests were mostly densely distributed around the natural forests in the southern region and loess hilly region in the central and eastern regions. Croplands were widely distributed in the central and western regions. Unused land and grasslands were distributed in the northern part of the study area (Figure 5a). Croplands attained the highest proportion $\left(5923.99 \mathrm{~km}^{2}\right.$ or $33.89 \%$ of the study area), followed by grasslands $\left(4192.97 \mathrm{~km}^{2}, 23.99 \%\right)$, planted forests $\left(3608.72 \mathrm{~km}^{2}, 20.60 \%\right)$, and unused land $\left(2149.20 \mathrm{~km}^{2}, 12.29 \%\right)$. Natural forests occupied only $6.58 \%\left(1149.43 \mathrm{~km}^{2}\right)$ of the study area (Figure $\left.5 \mathrm{~b}\right)$.

\section{Discussion}

\subsection{Uncertainty Analysis}

At pixel level, the classification uncertainty of a given pixel belonging to a certain land cover type was generally low based on the above accuracy evaluation results (Figure 6). The uncertainty value was less than 0.1 for at least $75 \%$ natural forest, unused land, built-up area, and waterbody pixels, was less than 0.2 and 0.3 for most regions for planted forests and grasslands. The relative high uncertainty for croplands might have resulted from orchards or unused land around the croplands [25]. 

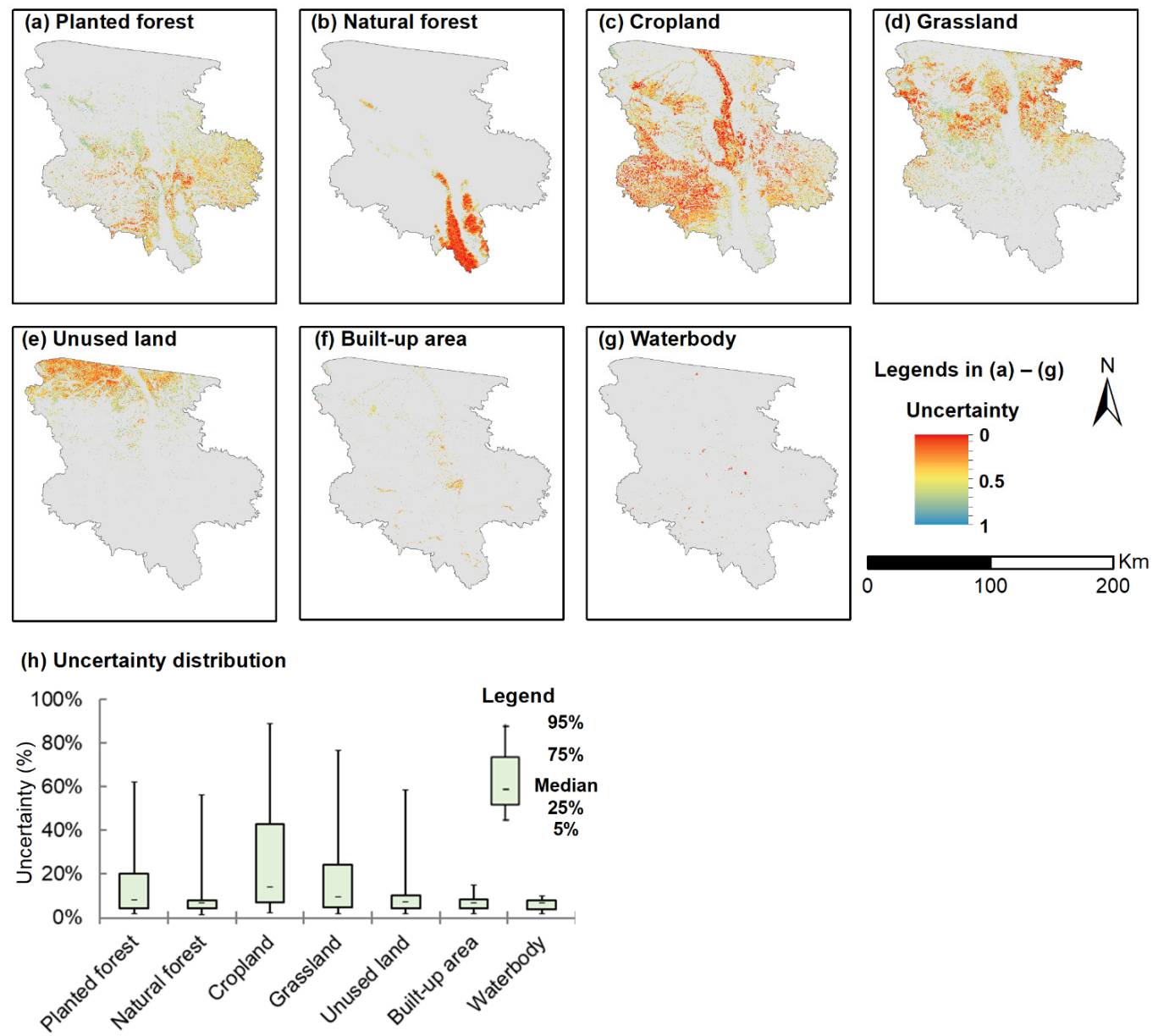

Figure 6. Uncertainties of a given pixel belonging to (a) planted forest, (b) natural forest, (c) cropland, (d) grassland, (e) unused land, (f) built-up area, and (g) waterbody, together with an (h) uncertainty distribution of the seven land cover types.

Other possible sources of uncertainty include sensor inconsistency, the number and quality of valid observations, and the effect of NDVI reconstruction model. Different satellite sensors may perform inconsistently for the land cover types. However, previous studies have already indicated high similarity of the Landsat sensors, and that plantation mapping can be performed well from the long time series [42,43]. Moreover, the harmonic regression of dense vegetation index time series could expand the utility of the Landsat [44]. In this study, the interannual change trend of NDVI based on the sensors of TM, ETM+ and OLI has been harmonized on GEE using the harmonic model HANTS. The verification analysis showed that $95 \%$ of root mean square error (RMSE) values of the HANTS fit were less than 0.1 , indicating that the inconsistencies between different satellite sensors could be negligible.

\subsection{Limitations and Direction of Future Studies}

Our land cover map achieved a satisfactory accuracy and a relatively low uncertainty. Planted forests could be distinguished using the long-term change trend derived from dense Landsat time series and machine learning classification. However, there are limitations and difficulties in the planted forest classification that should be addressed in future studies.

First, sufficient and representative reference samples are often decisive and remain a challenge in accurate supervised classification [45]. Nevertheless, spatiotemporally consistent collection (e.g., yearly or over a large area) of reference samples is expensive in terms of labor or time, infeasible in practice, and impossible over historical periods [46,47]. 
Therefore, it is necessary to develop an automatic land cover classification method for various time periods based on a small number of reference samples [48].

Second, ecological programs involving afforestation usually convert barren land, grasslands, or sloping farmlands into forests, with the aim to reduce soil erosion, restore ecosystem health, and improve local ecosystem quality $[49,50]$. Meanwhile, various shrub species, such as Caragana microphylla, are also planted because of their adaptive capacity to semiarid habitats. However, we did not distinguish planted shrublands from natural shrublands in our study, which may underestimate the effects of the ecological programs. It is valuable to provide scientific information on which species to plant by quantifying the characteristics of different vegetation types (trees or shrubs) [51].

In addition, certain planted forests share a few apparent similarities with grasslands in the extracted change magnitude and coefficient of variation features (Figure $4 \mathrm{~b}, \mathrm{e}$ ) because relatively young planted forests can be easily confused with grasslands [33]. In this case, segmentation temporal indicators derived from a subset of time windows and combination of change detection could be considered in future research.

Our algorithm is aimed at mapping planted forest based on long-term change trend features in an ecological restoration region, and the method can be reliable in arid and semi-arid regions with similar climates. As Landsat observations are insufficient in other regions, we intend to further pursue the time series reconstruction method considering spatial and temporal fusion. In addition, the effective long-term change trend features can provide a scientific foundation for automatic mapping of planted forests in other regions. To be sure, the algorithm is applicable in arid and semi-arid regions, but in humid subtropical or tropical regions, such as southern China, there are usually herbs or shrubs before forestation. The NDVI value of these vegetation are usually high, which may affect the applicability of NDVI change trend features.

\section{Conclusions}

In this study, by combining long-term change trend features derived from remote sensing time series and the random forest machine learning model, we developed an effective approach to identify planted forests. Long-term change trend features are crucial for planted forest identification, which could improve the accuracy from approximately $76 \%$ by using vegetation index only to above $90 \%$. The landcover map achieved a high classification accuracy, with the overall accuracy of $93.65 \%$, the kappa coefficient of 0.92 , and high producer and user accuracies for both planted and natural forest classes (all above $91.0 \%$ ). This novel mapping method for planted forest and effective features provide a scientific foundation for automatic mapping of planted forests at large scales and over long periods in other regions, for the assessment of multiple ecosystem services and ecosystem stability of planted forests, and for the evaluation of the restoration effects of ecological programs.

Author Contributions: Conceptualization, Y.M. and Z.T.; methodology, Y.M.; software, C.W.; validation, Y.M. and C.W.; formal analysis, Y.M.; investigation, Y.M.; resources, Z.T.; data curation, Y.M.; writing — original draft preparation, Y.M.; writing—review and editing, Y.G. and Z.T.; visualization, C.W. and Y.G.; supervision, Z.T.; project administration, Z.T.; funding acquisition, Z.T. All authors have read and agreed to the published version of the manuscript.

Funding: This research has been supported by the National Key Research and Development Program of China (grant no. 2019YFA0606602), the National Natural Science Foundation of China (grant no. 32025025, 31988102, and U1910207).

Data Availability Statement: Planted forest mapping result are available online at https://code. earthengine.google.com/2cbdec1377f55e9092914975a0a7f69a (accessed on 10 August 2021).

Acknowledgments: We thank the Google Earth Engine platform for providing the geospatial datasets and complex algorithms (https: / / earthengine.google.com/ (accessed on 28 December 2021)).

Conflicts of Interest: No potential conflict of interest was reported by the authors. 


\section{Appendix A}

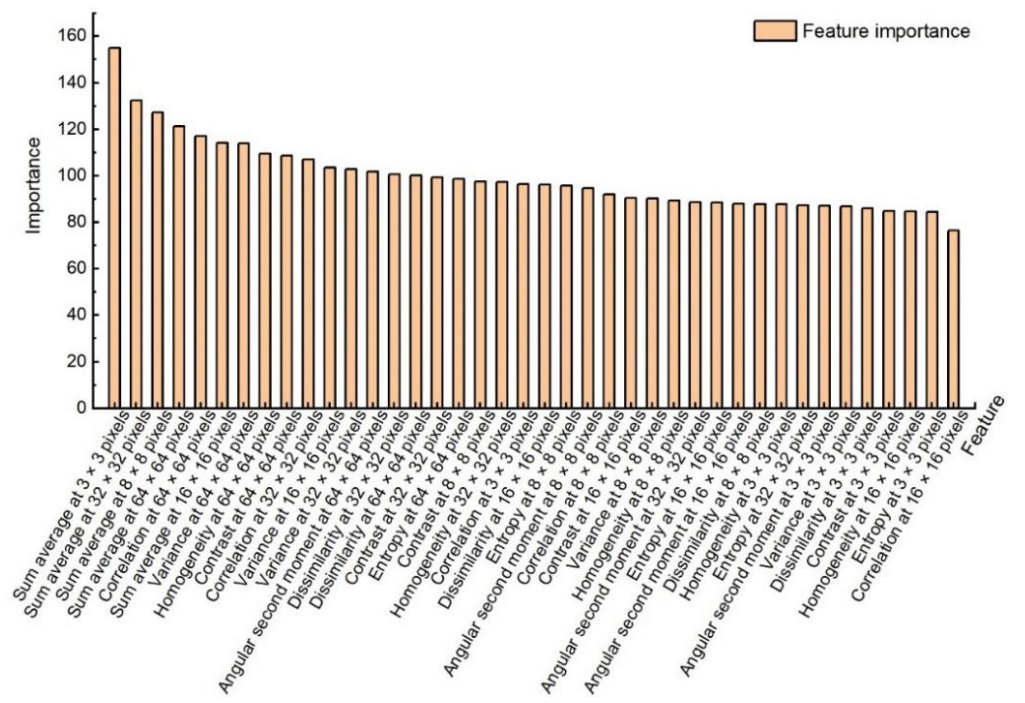

Figure A1. Importance of the features of the eight considered GLCM-based metrics under the different window sizes: $3 \times 3(90 \times 90 \mathrm{~m}), 8 \times 8(240 \times 240 \mathrm{~m}), 16 \times 16(480 \times 480 \mathrm{~m}), 32 \times 32$ $(960 \times 960 \mathrm{~m})$, and $64 \times 64(1920 \times 1920 \mathrm{~m})$.
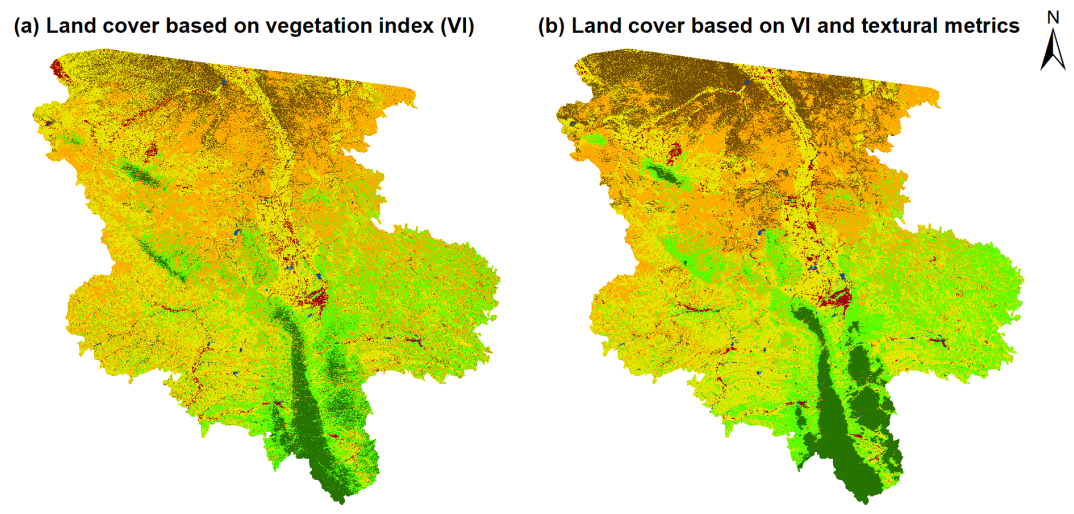

(c) Land cover based on $\mathrm{VI}$ and trend metrics
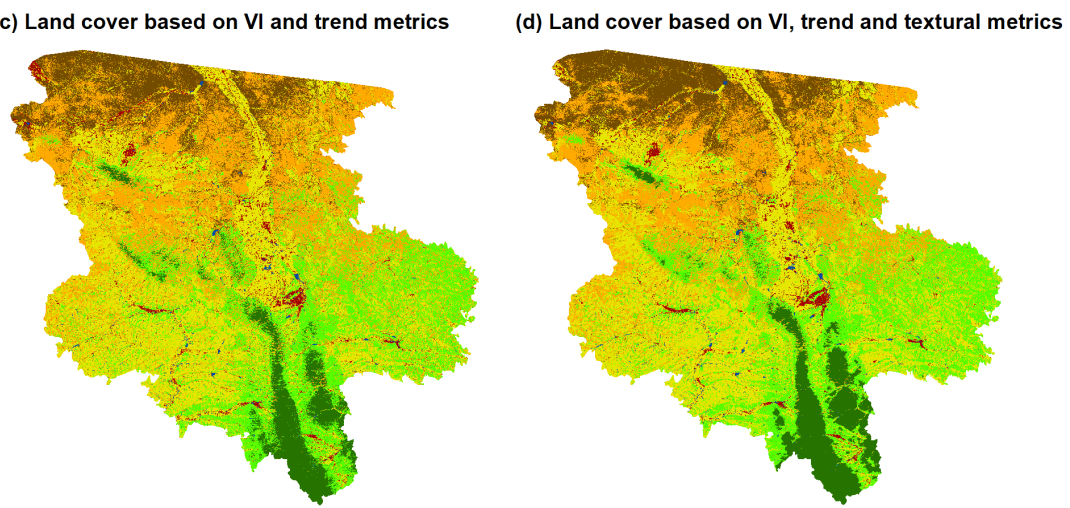

Legend
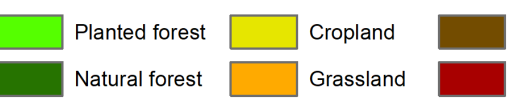

Unused land Built-up area

Waterbody

0

50

Figure A2. Land cover types classified based on the algorithm considering (a) the vegetation index (VI), (b) VI and textural metrics, (c) VI and long-term change trend metrics, and (d) VI, long-term change trend and textural metrics. 
Table A1. Vegetation indices considered in this study.

\begin{tabular}{|c|c|c|}
\hline Vegetation Index & Equations & References \\
\hline $\begin{array}{l}\text { Normalized Difference Vegetation Index } \\
\text { (NDVI) }\end{array}$ & $\mathrm{NDVI}=\frac{\rho_{\text {nir }}-\rho_{\text {red }}}{\rho_{\text {nir }}+\rho_{\text {red }}}$ & [52] \\
\hline Enhanced Vegetation Index (EVI) & $\begin{array}{c}\mathrm{EVI}=2.5 \times \\
\frac{\rho_{\text {nir }}-\rho_{\text {red }}}{\rho_{\text {rer }}+6 \times \rho_{\text {mad }}-7.5 \times \rho_{\text {ber }}+1}\end{array}$ & [53] \\
\hline Normalized Burn Ratio (NBR) & $\mathrm{NBR}=\frac{\rho_{\text {nir }}-\rho_{\text {swir } 2}}{\rho_{\text {nir }}+\rho_{\text {swir } 2}}$ & [54] \\
\hline Normalized Difference Built-up Index (NDBI) & $\mathrm{NDBI}=\frac{\rho_{\mathrm{swir} 1}-\rho_{\text {nir }}}{\rho_{\text {swir1 } 1}+\rho_{\text {nir }}}$ & [55] \\
\hline Normalized Difference Water Index (NDWI) & $\mathrm{NDWI}=\frac{\rho_{\text {green }}-\rho_{\text {nir }}}{\rho_{\text {green }}+\rho_{\text {nir }}}$ & [56] \\
\hline $\begin{array}{l}\text { Modified Normalized Difference Water Index } \\
\qquad(\text { MNDWI) }\end{array}$ & MNDWI $=\frac{\rho_{\text {green }}--\rho_{\text {swir1 }}}{\rho_{\text {green }}+\rho_{\text {swir1 } 1}}$ & [57] \\
\hline $\begin{array}{l}\text { Normalized Difference Phenology Index } \\
\text { (NDPI) }\end{array}$ & $\begin{array}{c}\text { NDPI }=\frac{\rho_{\text {nir }}-\left(\varphi * \rho_{\text {red }}+(1-\varphi) * \rho_{\text {swir } 1}\right)}{\rho_{\text {nir }}+\left(\varphi * \rho_{\text {red }}+(1-\varphi) * \rho_{\text {swir } 1}\right)} \\
\varphi=0.74\end{array}$ & [58] \\
\hline
\end{tabular}

where $\rho_{\text {blue }}, \rho_{\text {green }}, \rho_{\text {red }}, \rho_{\text {nir }}, \rho_{\text {swir1 }}$ and $\rho_{\text {swir2 }}$ denote the surface reflectances in blue, green, red, near-infrared and shortwave infrared 1 and 2 bands, respectively, of the Landsat sensor.

Table A2. Gray level co-occurrence texture features used in this study [37].

\begin{tabular}{|c|c|}
\hline Texture Features & Equations \\
\hline Angular second moment (ASM) & $\mathrm{ASM}=\sum_{\mathrm{i}, \mathrm{j}=1} \mathrm{C}_{\mathrm{ij}}^{2}$ \\
\hline Contrast $(\mathrm{CON})$ & $\mathrm{CON}=\sum_{\mathrm{i}, \mathrm{j}=1} \mathrm{C}_{\mathrm{ij}}\left(\mathrm{x}_{\mathrm{i}}-\mathrm{x}_{\mathrm{j}}\right)^{2}$ \\
\hline Correlation (COR) & $\mathrm{COR}=\sum_{\mathrm{i}, \mathrm{j}=1}\left[\left(\mathrm{x}_{\mathrm{i}}-\mu_{\mathrm{x}}\right)\left(\mathrm{x}_{\mathrm{j}}-\mu_{\mathrm{y}}\right) \mathrm{C}_{\mathrm{ij}}\right] /\left(\sigma_{\mathrm{x}} * \sigma_{\mathrm{y}}\right)$ \\
\hline Variance (VAR) & VAR $=\sum_{i, j=1}\left(x_{i}-\mu\right)^{2} C_{i j}$ \\
\hline Homogeneity (HOM) & $\mathrm{HOM}=\sum_{\mathrm{i}, \mathrm{j}=1} \mathrm{C}_{\mathrm{ij}} /\left(1+\left(\mathrm{x}_{\mathrm{i}}-\mathrm{x}_{\mathrm{j}}\right)^{2}\right)$ \\
\hline Sum average (SAVG) & $\mathrm{SAVG}=\sum_{\mathrm{k}=2}^{2 \mathrm{G}} \sum_{\substack{\mathrm{i}, \mathrm{j}=1 \\
\mathrm{i}+\mathrm{i}-\mathrm{k}}} \mathrm{C}_{\mathrm{ij}}, \quad \mathrm{k}=2,3, \ldots, 2 \mathrm{G}$ \\
\hline Entropy (ENT) & $\mathrm{ENT}=-\sum_{\mathrm{i}, \mathrm{j}=1} \mathrm{C}_{\mathrm{ij}} \log _{2} \mathrm{C}_{\mathrm{ij}}$ \\
\hline \multicolumn{2}{|l|}{ Dissimilarity (DIS) } \\
\hline \multirow{2}{*}{\multicolumn{2}{|c|}{$\begin{array}{l}\text { where } x_{i} \text { and } x_{j} \text { denote the NDVI values of pixel } i \text { and its neighbor pixel } j \text {, respectively, } \mu \text { is the mean of the GLCM } \\
\text { matrix, } \mu_{x} \text { and } \mu_{y} \text { and } \sigma_{x} \text { and } \sigma_{y} \text { are the means and standard deviations, respectively, of the matrix rows and } \\
\text { columns, respectively, and } C_{i j} \text { is the probability distribution of pairs of gray levels, as defined in Equation (4). } \\
\text { Table A3. Land cover types and class definitions according to the land use/cover classification } \\
\text { (LUCC) system. }\end{array}$}} \\
\hline & \\
\hline Land Cover Types & Description \\
\hline \multirow{2}{*}{$\begin{array}{l}\text { Planted forest } \\
\text { Natural forest }\end{array}$} & Planted trees, shrubs, bamboo and other forest vegetation. \\
\hline & $\begin{array}{l}\text { Natural trees, shrubs, bamboo and other forest vegetation. } \\
\text { Land for crop planting, including cultivated land, newly }\end{array}$ \\
\hline Cropland & $\begin{array}{c}\text { reclaimed land, fallow land, rotation and rest land, and } \\
\text { cereal croplands. }\end{array}$ \\
\hline & Dominated by herbaceous vegetation. \\
\hline Unused land & Nonvegetated barren (sand, rock, and soil) areas. \\
\hline Built-up area & $\begin{array}{l}\text { Land for industrial activities, mining and vehicles in urban } \\
\text { and rural residential areas. }\end{array}$ \\
\hline Waterbody & $\begin{array}{l}\text { Covered by permanent water bodies and water } \\
\text { conservancy facilities. }\end{array}$ \\
\hline
\end{tabular}




\section{References}

1. Tong, X.W.; Brandt, M.; Yue, Y.M.; Horion, S.; Wang, K.L.; De Keersmaecker, W.; Tian, F.; Schurgers, G.; Xiao, X.M.; Luo, Y.Q.; et al. Increased vegetation growth and carbon stock in China karst via ecological engineering. Nat. Sustain. 2018, 1, 44-50. [CrossRef]

2. Wang, Z.; Peng, D.; Xu, D.; Zhang, X.; Zhang, Y. Assessing the water footprint of afforestation in Inner Mongolia, China. J. Arid Environ. 2020, 182, 104257. [CrossRef]

3. Cao, S.; Chen, L.; Shankman, D.; Wang, C.; Wang, X.; Zhang, H. Excessive reliance on afforestation in China's arid and semi-arid regions: Lessons in ecological restoration. Earth-Sci. Rev. 2011, 104, 240-245. [CrossRef]

4. Wang, Y.H.; Brandt, M.; Zhao, M.F.; Tong, X.W.; Xing, K.X.; Xue, F.; Kang, M.Y.; Wang, L.H.; Jiang, Y.; Fensholt, R. Major forest increase on the Loess Plateau, China (2001-2016). Land Degrad. Dev. 2018, 29, 4080-4091. [CrossRef]

5. Zhang, Y.; Peng, C.H.; Li, W.Z.; Tian, L.X.; Zhu, Q.Q.; Chen, H.; Fang, X.Q.; Zhang, G.L.; Liu, G.M.; Mu, X.M.; et al. Multiple afforestation programs accelerate the greenness in the 'Three North' region of China from 1982 to 2013. Ecol. Indic. 2016, 61, 404-412. [CrossRef]

6. $\quad$ Fassnacht, F.E.; Latifi, H.; Sterenczak, K.; Modzelewska, A.; Lefsky, M.; Waser, L.T.; Straub, C.; Ghosh, A. Review of studies on tree species classification from remotely sensed data. Remote Sens. Environ. 2016, 186, 64-87. [CrossRef]

7. Griffiths, P.; Kuemmerle, T.; Baumann, M.; Radeloff, V.C.; Abrudan, I.V.; Lieskovsky, J.; Munteanu, C.; Ostapowicz, K.; Hostert, P. Forest disturbances, forest recovery, and changes in forest types across the Carpathian ecoregion from 1985 to 2010 based on Landsat image composites. Remote Sens. Environ. 2014, 151, 72-88. [CrossRef]

8. Spracklen, B.; Spracklen, D.V. Synergistic Use of Sentinel-1 and Sentinel-2 to map natural forest and acacia plantation and stand ages in North-Central Vietnam. Remote Sens. 2021, 13, 185. [CrossRef]

9. Tropek, R.; Sedlacek, O.; Beck, J.; Keil, P.; Musilova, Z.; Simova, I.; Storch, D. Comment on “High-resolution global maps of 21st-century forest cover change". Science 2014, 344, 3. [CrossRef]

10. Ye, S.; Rogan, J.; Sangermano, F. Monitoring rubber plantation expansion using Landsat data time series and a Shapelet-based approach. Isprs J. Photogramm. Remote Sens. 2018, 136, 134-143. [CrossRef]

11. Chazdon, R.L.; Brancalion, P.H.S.; Laestadius, L.; Bennett-Curry, A.; Buckingham, K.; Kumar, C.; Moll-Rocek, J.; Vieira, I.C.G.; Wilson, S.J. When is a forest a forest? Forest concepts and definitions in the era of forest and landscape restoration. Ambio 2016, 45, 538-550. [CrossRef] [PubMed]

12. Xi, W.Q.; Du, S.H.; Du, S.H.; Zhang, X.Y.; Gu, H.Y. Intra-annual land cover mapping and dynamics analysis with dense satellite image time series: A spatiotemporal cube based spatiotemporal contextual method. Giscience Remote Sens. 2021, 58, 1195-1218. [CrossRef]

13. Ji, Q.; Liang, W.; Fu, B.; Zhang, W.; Yan, J.; Lu, Y.; Yue, C.; Jin, Z.; Lan, Z.; Li, S.Y.; et al. Mapping land use/cover dynamics of the Yellow River Basin from 1986 to 2018 supported by Google Earth Engine. Remote Sens. 2021, 13, 1299. [CrossRef]

14. Li, Y.C.; Liu, C.L.; Zhang, J.; Zhang, P.; Xue, Y.F. Monitoring spatial and temporal patterns of rubber plantation dynamics using time-series Landsat images and Google Earth Engine. IEEE J. Sel. Top. Appl. Earth Observ. Remote Sens. 2021, 14, 9450-9461. [CrossRef]

15. Poortinga, A.; Tenneson, K.; Shapiro, A.; Quyen, N.; San Aung, K.; Chishtie, F.; Saah, D. Mapping plantations in Myanmar by fusing Landsat-8, Sentinel-2 and Sentinel-1 data along with systematic error quantification. Remote Sens. 2019, 11, 831. [CrossRef]

16. Heilmayr, R.; Echeverria, C.; Fuentes, R.; Lambin, E.F. A plantation-dominated forest transition in Chile. Appl. Geogr. 2016, 75, 71-82. [CrossRef]

17. Gao, T.; Zhu, J.; Zheng, X.; Shang, G.; Huang, L.; Wu, S. Mapping spatial distribution of larch plantations from multi-seasonal Landsat-8 OLI imagery and multi-scale textures using Random Forests. Remote Sens. 2015, 7, 1702-1720. [CrossRef]

18. Kou, W.; Dong, J.; Xiao, X.; Hernandez, A.J.; Qin, Y.; Zhang, G.; Chen, B.; Lu, N.; Doughty, R. Expansion dynamics of deciduous rubber plantations in Xishuangbanna, China during 2000-2010. Gisci. Remote Sens. 2018, 55, 905-925. [CrossRef]

19. Torbick, N.; Ledoux, L.; Salas, W.; Zhao, M. Regional mapping of plantation extent using multisensor imagery. Remote Sens. 2016, 8, 236. [CrossRef]

20. Qiu, B.W.; Zou, F.L.; Chen, C.C.; Tang, Z.H.; Zhong, J.P.; Yan, X.F. Automatic mapping afforestation, cropland reclamation and variations in cropping intensity in central east China during 2001-2016. Ecol. Indic. 2018, 91, 490-502. [CrossRef]

21. Dong, J.; Xiao, X.; Chen, B.; Torbick, N.; Jin, C.; Zhang, G.; Biradar, C. Mapping deciduous rubber plantations through integration of PALSAR and multi-temporal Landsat imagery. Remote Sens. Environ. 2013, 134, 392-402. [CrossRef]

22. Bey, A.; Meyfroidt, P. Improved land monitoring to assess large-scale tree plantation expansion and trajectories in Northern Mozambique. Environ. Res. Commun. 2021, 3, 14. [CrossRef]

23. Fagan, M.E.; Morton, D.C.; Cook, B.D.; Masek, J.; Zhao, F.; Nelson, R.F.; Huang, C. Mapping pine plantations in the southeastern US using structural, spectral, and temporal remote sensing data. Remote Sens. Environ. 2018, 216, 415-426. [CrossRef]

24. Yu, Z.; Zhao, H.; Liu, S.; Zhou, G.; Fang, J.; Yu, G.; Tang, X.; Wang, W.; Yan, J.; Wang, G.; et al. Mapping forest type and age in China's plantations. Sci. Total Environ. 2020, 744, 140790. [CrossRef] [PubMed]

25. Liu, L.Y.; Tang, H.; Caccetta, P.; Lehmann, E.A.; Hu, Y.; Wu, X. Mapping afforestation and deforestation from 1974 to 2012 using Landsat time-series stacks in Yulin District, a key region of the Three-North Shelter region, China. Environ. Monit. Assess. 2013, 185, 9949-9965. [CrossRef] [PubMed]

26. Wang, F.; Pan, X.; Gerlein-Safdi, C.; Cao, X.; Wang, S.; Gu, L.; Wang, D.; Lu, Q. Vegetation restoration in Northern China: A contrasted picture. Land Degrad. Dev. 2020, 31, 669-676. [CrossRef] 
27. Kim, J.; Song, C.; Lee, S.; Jo, H.; Park, E.; Yu, H.N.; Cha, S.; An, J.; Son, Y.; Khamzina, A.; et al. Identifying potential vegetation establishment areas on the dried Aral Sea floor using satellite images. Land Degrad. Dev. 2020, 31, 2749-2762. [CrossRef]

28. Li, S.; Yang, S.; Liu, X.; Liu, Y.; Shi, M. NDVI-based analysis on the influence of climate change and human activities on vegetation restoration in the Shaanxi-Gansu-Ningxia Region, Central China. Remote Sens. 2015, 7, 11163-11182. [CrossRef]

29. Yang, J.; Huang, X. The $30 \mathrm{~m}$ annual land cover dataset and its dynamics in China from 1990 to 2019. Earth Syst. Sci. Data 2021, 13, 3907-3925. [CrossRef]

30. Zhu, Z.; Woodcock, C.E.; Olofsson, P. Continuous monitoring of forest disturbance using all available Landsat imagery. Remote Sens. Environ. 2012, 122, 75-91. [CrossRef]

31. Roy, D.P.; Kovalskyy, V.; Zhang, H.K.; Vermote, E.F.; Yan, L.; Kumar, S.S.; Egorov, A. Characterization of Landsat-7 to Landsat-8 reflective wavelength and normalized difference vegetation index continuity. Remote Sens. Environ. 2016, 185, 57-70. [CrossRef] [PubMed]

32. Pan, N.; Feng, X.; Fu, B.; Wang, S.; Ji, F.; Pan, S. Increasing global vegetation browning hidden in overall vegetation greening: Insights from time-varying trends. Remote Sens. Environ. 2018, 214, 59-72. [CrossRef]

33. Yao, Y.; Piao, S.; Wang, T. Future biomass carbon sequestration capacity of Chinese forests. Sci. Bull. 2018, 63, 1108-1117. [CrossRef]

34. Wilson, B.T.; Knight, J.F.; McRoberts, R.E. Harmonic regression of Landsat time series for modeling attributes from national forest inventory data. Isprs J. Photogramm. Remote Sens. 2018, 137, 29-46. [CrossRef]

35. Sellers, P.J.; Tucker, C.J.; Collatz, G.J.; Los, S.O.; Justice, C.O.; Dazlich, D.A.; Randall, D.A. A revised land surface parameterization (SiB2) for atmospheric GCMS. Part II: The generation of global fields of terrestrial biophysical parameters from satellite data. $J$. Clim. 1996, 9, 706-737. [CrossRef]

36. Song, D.; Huang, C.; Sexton, J.O.; Channan, S.; Feng, M.; Townshend, J.R. Use of Landsat and Corona data for mapping forest cover change from the mid-1960s to 2000s: Case studies from the Eastern United States and Central Brazil. Isprs J. Photogramm. Remote Sens. 2015, 103, 81-92. [CrossRef]

37. Tuominen, S.; Pekkarinen, A. Performance of different spectral and textural aerial photograph features in multi-source forest inventory. Remote Sens. Environ. 2005, 94, 256-268. [CrossRef]

38. Farr, T.G.; Rosen, P.A.; Caro, E.; Crippen, R.; Duren, R.; Hensley, S.; Kobrick, M.; Paller, M.; Rodriguez, E.; Roth, L.; et al. The shuttle radar topography mission. Rev. Geophys. 2007, 45, 33. [CrossRef]

39. Olofsson, P.; Foody, G.M.; Herold, M.; Stehman, S.V.; Woodcock, C.E.; Wulder, M.A. Good practices for estimating area and assessing accuracy of land change. Remote Sens. Environ. 2014, 148, 42-57. [CrossRef]

40. Cao, B.; Yu, L.; Naipal, V.; Ciais, P.; Li, W.; Zhao, Y.; Wei, W.; Chen, D.; Liu, Z.; Gong, P. A 30-meter terrace mapping in China using Landsat 8 imagery and digital elevation model based on the Google Earth Engine. Earth Syst. Sci. Data 2021, 13, 2437-2456. [CrossRef]

41. Loosvelt, L.; Peters, J.; Skriver, H.; Lievens, H.; Van Coillie, F.M.B.; De Baets, B.; Verhoest, N.E.C. Random Forests as a tool for estimating uncertainty at pixel-level in SAR image classification. Int. J. Appl. Earth Obs. Geoinf. 2012, 19, 173-184. [CrossRef]

42. Zhu, Z.; Fu, Y.C.; Woodcock, C.E.; Olofsson, P.; Vogelmann, J.E.; Holden, C.; Wang, M.; Dai, S.; Yu, Y. Including land cover change in analysis of greenness trends using all available Landsat 5, 7, and 8 images: A case study from Guangzhou, China (2000-2014). Remote Sens. Environ. 2016, 185, 243-257. [CrossRef]

43. Zhu, Z.; Woodcock, C.E.; Holden, C.; Yang, Z.Q. Generating synthetic Landsat images based on all available Landsat data: Predicting Landsat surface reflectance at any given time. Remote Sens. Environ. 2015, 162, 67-83. [CrossRef]

44. Vogeler, J.C.; Braaten, J.D.; Slesak, R.A.; Falkowski, M.J. Extracting the full value of the Landsat archive: Inter-sensor harmonization for the mapping of Minnesota forest canopy cover (1973-2015). Remote Sens. Environ. 2018, 209, 363-374. [CrossRef]

45. Amani, M.; Brisco, B.; Afshar, M.; Mirmazloumi, S.M.; Mahdavi, S.; Mirzadeh, S.M.; Huang, W.; Granger, J. A generalized supervised classification scheme to produce provincial wetland inventory maps: An application of Google Earth Engine for big geo data processing. Big Earth Data 2019, 3, 378-394. [CrossRef]

46. Hu, J.; Xia, G.S.; Hu, F.; Zhang, L.P. A comparative study of sampling analysis in the scene classification of optical high-spatial resolution remote sensing imagery. Remote Sens. 2015, 7, 14988-15013. [CrossRef]

47. Tong, X.Y.; Xia, G.S.; Lu, Q.K.; Shen, H.F.; Li, S.Y.; You, S.C.; Zhang, L.P. Land-cover classification with high-resolution remote sensing images using transferable deep models. Remote Sens. Environ. 2020, 237, 20. [CrossRef]

48. Ghorbanian, A.; Kakooei, M.; Amani, M.; Mahdavi, S.; Mohammadzadeh, A.; Hasanlou, M. Improved land cover map of Iran using Sentinel imagery within Google Earth Engine and a novel automatic workflow for land cover classification using migrated training samples. ISPRS J. Photogramm. Remote Sens. 2020, 167, 276-288. [CrossRef]

49. Chen, Y.; Wang, K.; Lin, Y.; Shi, W.; Song, Y.; He, X. Balancing green and grain trade. Nat. Geosci. 2015, 8, 739-741. [CrossRef]

50. Chen, P.; Shang, J.; Qian, B.; Jing, Q.; Liu, J. A new regionalization scheme for effective ecological restoration on the Loess Plateau in China. Remote Sens. 2017, 9, 1323. [CrossRef]

51. Gelviz-Gelvez, S.M.; Pavon, N.P.; Illoldi-Rangel, P.; Ballesteros-Barrera, C. Ecological niche modeling under climate change to select shrubs for ecological restoration in Central Mexico. Ecol. Eng. 2015, 74, 302-309. [CrossRef]

52. Tucker, C.J. Red and photographic infrared linear combinations for monitoring vegetation. Remote Sens. Environ. 1979, 8, 127-150. [CrossRef] 
53. Huete, A.; Didan, K.; Miura, T.; Rodriguez, E.P.; Gao, X.; Ferreira, L.G. Overview of the radiometric and biophysical performance of the MODIS vegetation indices. Remote Sens. Environ. 2002, 83, 195-213. [CrossRef]

54. Key, C.H.; Benson, N.C. Landscape assessment: Sampling and analysis methods. In General Technical Report RMRS-GTR-164-CD; USDA Forest Service, Rocky Mountain Research Station: Fort Collins, CO, USA, 2006; pp. 1-55.

55. Zha, Y.; Gao, J.; Ni, S. Use of normalized difference built-up index in automatically mapping urban areas from TM imagery. Int. J. Remote Sens. 2003, 24, 583-594. [CrossRef]

56. McFeeters, S.K. The use of the normalized difference water index (NDWI) in the delineation of open water features. Int. J. Remote Sens. 1996, 17, 1425-1432. [CrossRef]

57. Xu, H.Q. Modification of normalised difference water index (NDWI) to enhance open water features in remotely sensed imagery. Int. J. Remote Sens. 2006, 27, 3025-3033. [CrossRef]

58. Wang, C.; Chen, J.; Wu, J.; Tang, Y.H.; Shi, P.J.; Black, T.A.; Zhu, K. A snow-free vegetation index for improved monitoring of vegetation spring green-up date in deciduous ecosystems. Remote Sens. Environ. 2017, 196, 1-12. [CrossRef] 